\title{
Fondos de Pensiones y Criterios Éticos de Inversión
}

Juan Ignacio Latorre R. ${ }^{1}$

Dr. (c) Gestión Avanzada de Organizaciones y Economía Social, Universidad de Mondragón (Euskadi).

Director Centro de Ética y Reflexión Social Fernando Vives SJ.

Universidad Alberto Hurtado

\section{Los fondos de pensiones que actualmente administran} las AFP acumulan unos US\$ 170 mil millones, equivalente a un $70 \%$ del PIB de Chile. Estas invierten con criterios de optimización de rentabilidad y riesgo en distintos instrumentos del mercado de capitales nacional y en el sistema financiero internacional. El artículo considera la posibilidad de incorporar complementariamente criterios éticos de inversión y revisa experiencias internacionales donde se aplican dichos criterios, tales como Noruega, Suecia y Canadá. Se plantean algunas reflexiones en torno a la potencial contribución de los fondos de pensiones al Desarrollo Sostenible en Chile.

¿En qué se invierten los fondos de pensiones chilenos?

Cuando se comparan los flujos del sistema privado de pensiones, se puede observar que cada año se generan altos excedentes disponibles para ser invertidos en el mercado de capitales, dado que lo recaudado vía cotizaciones y aportes del Fisco (bonos de reconocimiento, pensiones mínimas garantizadas, Aporte Previsional Solidario, Pensión Básica Solidaria y otros subsidios) supera con creces al pago de beneficios. Por ejemplo, el 2013 (según datos de la Superintendencia de AFP) mientras se recibieron ahorros previsionales por casi $\$ 6,6$ billones, se pagaron beneficios por sólo $\$ 2,5$ billones, arrojando un excedente de $\$ 4,1$ billones que equivale al $62 \%$ de las contribuciones aportadas por los trabajadores. Este flujo mensual proveniente del salario de la fuerza de trabajo que cotiza en las AFP está disponible para ser invertido en distintos instrumentos del sistema económico nacional e internacional.
Actualmente los criterios preferenciales utilizados para realizar inversiones con el fondo de pensiones tienen relación con la rentabilidad financiera y la exposición al riesgo. A nivel nacional se invierte en distintos instrumentos financieros tales como: acciones de sociedades anónimas, bonos de empresas públicas y privadas, en distintos sectores económicos (eléctricas, industrial, recursos naturales, servicios, telecomunicaciones), y de los principales grupos económicos del país (SVS, 2016).

\footnotetext{
1 Correo electrónico jlatorre@uahurtado.cl
} 
Regulación de las inversiones de los fondos de pensiones

Las administradoras diseñan sus estrategias de inversión con el objeto de maximizar su rentabilidad para un nivel de riesgo, en conformidad con la regulación vigente (DL 3.500) En términos generales, esta regulación intenta mantener niveles acotados de riesgo (rating crediticio), liquidez (facilidad para vender al precio de mercado) y diversificación de inversiones (entre sectores económicos, tipo de activos financieros y ubicación geográfica).

Específicamente, las inversiones de los Fondos de Pensiones se regulan principalmente por las disposiciones del Decreto Ley 3.500 de 1980, el Régimen de Inversión de los Fondos de Pensiones y por la normativa complementaria dictada por la Superintendencia de Pensiones.

La Ley de Reforma al Sistema Previsional del 2008 (Ley N. 20.255) introdujo un conjunto de modificaciones al DL 3.500 que en el ámbito de las inversiones de los Fondos de Pensiones se orientaron a perfeccionar y flexibilizar la legislación, dando los lineamientos generales de la elegibilidad de los instrumentos, los límites estructurales para la inversión de los fondos y los límites respecto de emisores que evitan concentración de propiedad y participación en el control por parte de los fondos de pensiones (SP, 2013).

Adicionalmente, existe un Consejo Técnico de Inversiones (CTI) al que le corresponde ejercer las funciones y atribuciones señaladas en el artículo 167 del DL 3.500. El CTI debe pronunciarse sobre todas las materias contenidas en el Régimen de inversión, emitiendo opiniones técnicas y proponiendo perfeccionamientos al citado Régimen. El CTI está integrado por cinco miembros, uno de ellos designado por el Presidente de la República, otro por el Consejo del Banco Central de Chile, otro por las Administradoras de Fondos de Pensiones (AFP) y dos de ellos designados por los Decanos de las Facultades de Economía y Administración de las Universidades que se encuentren acreditadas. No existe representación de los trabajadores afiliados a las AFP ni de los jubilados. Tampoco existe un Consejo Ético de Inversiones que supervise la implementación de criterios éticos de desarrollo sostenible de las inversiones.

\section{Más allá de la rentabilidad y riesgo: criterios éticos de desarrollo sostenible}

Un reciente estudio (López, 2016) muestra que la rentabilidad sobre patrimonio promedio de $25,4 \%$ alcanzado por las AFP en el periodo 20062015 fue 4,8 veces superior al 5,3\% justificable por su exposición al riesgo de mercado. En términos monetarios, de los US\$4.500 millones obtenidos por la industria en la última década, más de US\$3.500 millones corresponderían a una ganancia "excesiva". El contraste de estas grandes utilidades para la industria con las bajas pensiones que reciben la mayoría de los afiliados es uno de los factores (entre otros) del déficit de legitimidad social que tiene el sistema AFP en Chile, como lo demuestran los datos de un estudio encargado por la Comisión Asesora Presidencial (Comisión de Pensiones, 2015).

El modelo AFP ha sido un negocio muy rentable para sus dueños y muy exitoso para el desarrollo del mercado de capitales chileno, proporcionando financiamiento en condiciones favo- rables a los grandes grupos económicos, lo que ha contribuido (entre otros factores) a la generación, acumulación y concentración de la riqueza en Chile, siendo el país más desigual de la OCDE (2015).

Más allá de las utilidades y excedentes que genera este sistema privado de ahorro basado en la capitalización individual, surge la interrogante sobre el tipo de inversiones que se realizan, de ahí que las preguntas que aborda este artículo son las siguientes: ¿Se podrían incorporar criterios éticos a las inversiones que se hacen con el fondo de pensiones? ¿Las inversiones podrían contribuir a un modelo de desarrollo sostenible? ¿Qué dice la experiencia internacional comparada?

\section{Experiencia internacional}

El Ministerio de Finanzas de Noruega elaboró el 2004 los Lineamientos Éticos del Fondo de Pensiones. Los principales objetivos de estos lineamientos son la obtención de sólidos retornos financieros así como el respeto de los derechos fundamentales de las personas impactadas por las empresas en las que invierte el Fondo.

Los Lineamientos Éticos son transparentes y predecibles y se basan en una serie de normas reconocidas internacionalmente, tales como el Pacto Mundial de las Naciones Unidas y las Directrices de la OCDE para las empresas multinacionales ${ }^{2}$. El Fondo evitará invertir en empresas cuyas prácticas constituyan un inaceptable riesgo de que sea, o pueda ser, cómplice de actividades consideradas poco éticas. La decisión última de excluir a una empresa de las inversiones del Fondo está en manos del Ministerio de Finanzas, pero se basa en las recomendaciones de un Consejo de Ética independiente, las cuales están

(2) Estas directrices dicen relación con elevar estándares en relaciones laborales, derechos de los consumidores, protección del medioambiente, transparencia, lucha contra la corrupción, cuestiones tributarias, ciencia y tecnología, libre competencia, DDHH. Para mayor información ver http://www.oecd.org/daf/inv/ mne/MNEguidelinesESPANOL.pdf 
disponibles a la ciudadanía para dotar de legitimidad social las decisiones estratégicas y diversificadas de inversión a largo plazo 3 .

En Suecia, tienen un fondo de pensiones con inversiones responsables y sostenibles ambientalmente, según criterios éticos previamente establecidos (Second AP, 2015). Buscan rentabilidad segura a largo plazo en compañías que presenten un buen desempeño con sus stakeholders, y ejerciendo influencia desde las juntas directivas, a través de la gobernanza de la empresa cuando tienen una parte significativa de la propiedad. Tienen un consejo ético de inversiones para los distintos fondos de pensiones, el cual cumple un rol consultivo cuando se decide excluir a alguna empresa o retirar la inversión de una compañía que esté en conflicto con los criterios éticos y/o convenciones internacionales. También este consejo ético busca el diálogo con las empresas para solucionar problemas que se detecten y recomienda invertir donde se genere una mayor contribución al desarrollo sostenible.

En Canadá, específicamente en la región de Quebec, existe un Fondo de Pensiones solidario compuesto por las contribuciones voluntarias de los miembros de la Federación de Trabajadores de Quebec y ciudadanos independientes. La creación del Fondo le proporciona los recursos al movimiento sindical para participar en el desarrollo económico por medio de su capacidad de invertir directamente en empresas y sectores donde están aseguradas la creación y la seguridad de empleo decente, con sindicalización y negociación colectiva. Para proteger a sus miembros, el Fondo también se comprometió a invertir un gran porcentaje de sus recursos en inversiones seguras con razonables tasas de interés.

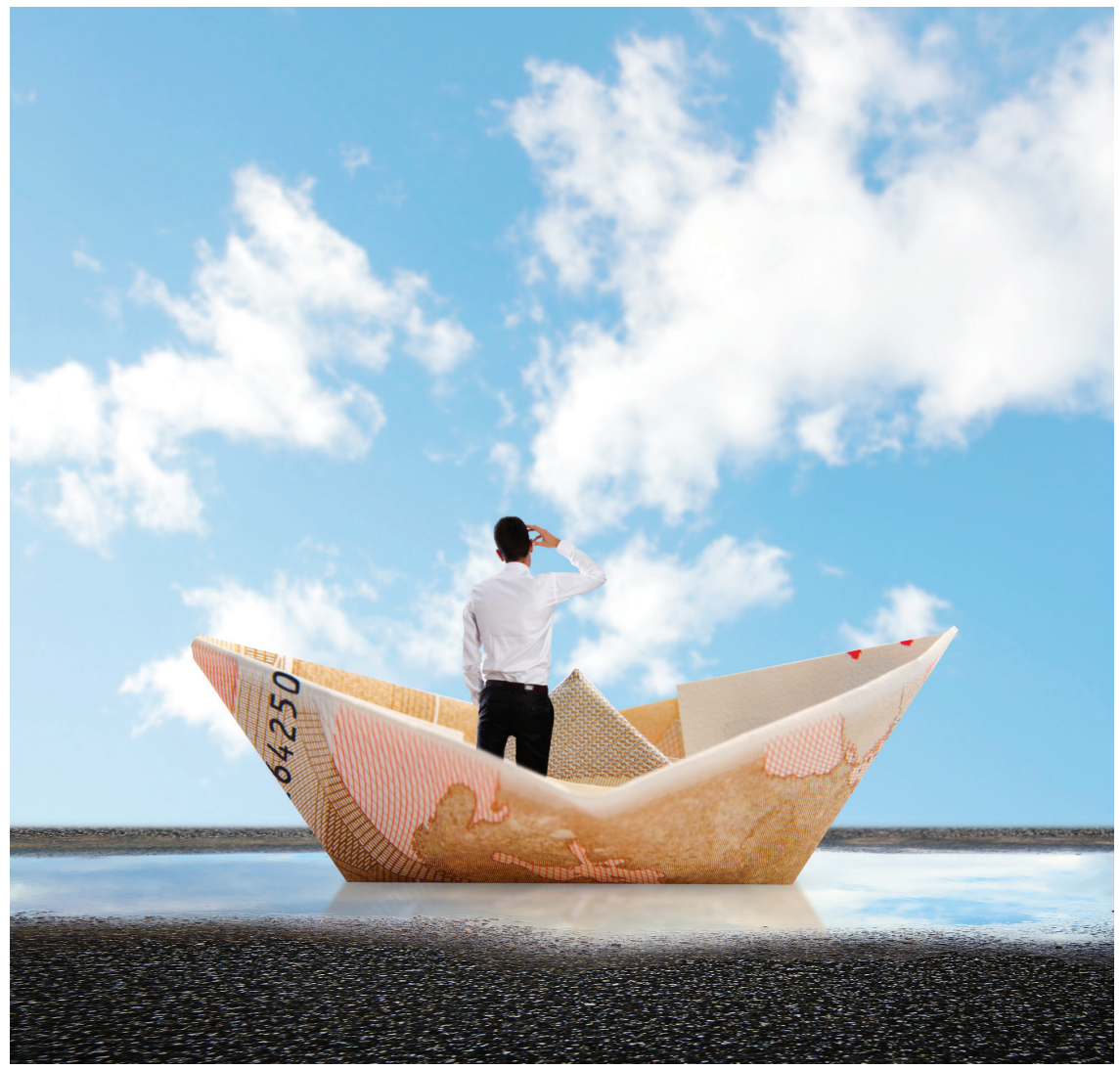

El establecimiento del Fondo en 1983 requirió legislación provincial y federal; se crearon generosos incentivos fiscales para atraer miembros. Mientras algunos remarcan los impresionantes resultados financieros, otros enfatizan la importancia en la capacidad que le da al movimiento laboral de participar directamente en el desarrollo económico, y el papel vital que tuvo el gobierno en este modelo.

La Confederación de Sindicatos $\mathrm{Na}$ cionales (CSN) también estableció un fondo solidario en 1996, Fondaction ${ }^{4}$ , diseñado para llevar a cabo objetivos socioeconómicos y disfruta de las mismas ventajas fiscales que el Fondo de solidaridad. Ambos han aportado significativamente a la capitalización de empresas de la economía social y solidaria, a la innovación social, al desarrollo local y sostenible de la región (Etxezarreta et al, 2015).

\section{Reflexiones finales y conclusiones}

Para concluir este breve artículo sobre criterios éticos de inversión a través del fondo de pensiones, me parece relevante citar al académico de Loyola University Chicago, David Schweickart (2011), quien propone el modelo de la Democracia Económica como alternativa a un sistema neoliberal financiarizado, especulativo, generador de desigualdades e insostenible social y medioambientalmente: "estamos en una situación difícil. Quienes están preocupados por incrementar el empleo nos urgen a gastar, gastar y gastar, mientras los ecologistas contestan a gritos que nuestra adicción al consumo está acabando con el planeta. Ambas partes tienen razón. Es más, ambas desean alcanzar el mismo fin: una economía sana y estable, con pleno

(3) El Fondo de Pensiones de Noruega asciende a más de US\$375 mil millones. Ver http://www.norges-bank.no/en/about/Organisation/The-Executive-Board/ (4) Ver http://www.fondaction.com/english.php 
empleo y tan sostenible como para ser capaz de pisar ligero sobre nuestro frágil planeta. ¿Acaso no es esto lo que todos deseamos?"

La pregunta por incorporar criterios éticos de inversión que busquen rentabilidad social, ambiental y financiera se enmarca en la búsqueda de un desarrollo sostenible, donde el crecimiento económico es un medio y no un fin en sí mismo. Chile acaba de firmar la agenda de Naciones Unidas sobre los Objetivos de Desarrollo Sostenible (ODS) al 2030. Los 17 ODS son un imperativo de ética social: fin de la pobreza, hambre cero, salud y bienestar, educación de calidad, igualdad de género, agua limpia y saneamiento, energía asequible y no contaminante, trabajo decente y crecimiento económico, industria, innovación e infraestructura, reducción de las desigualdades, ciudades y comunidades sostenibles, producción y consumo responsables, acción por el clima, protección de la vida submarina, respeto a la vida de ecosistemas terrestres, paz, justicia e instituciones sólidas, alianzas público-privadas para lograr los objetivos.

¿Es posible diseñar instrumentos de inversión para colaborar con el logro de los ODS al año 2030 mediante los fondos de pensiones? Obviamente hay que considerar el triple impacto económico, social y ambiental de las inversiones, ya que se tiene que manejar con mucha responsabilidad el fondo acumulado en las cuentas individuales de los afiliados a las AFP. En este contexto, uno de los cambios regulatorios que se podría realizar es permitir un representante de los afiliados con derecho a voz y voto en el comité técnico de inversiones, para introducir criterios éticos negativos y positivos que orienten las decisiones. La participación en la gestión de los fondos de pensiones es uno de los Principios de la Seguridad Social según OIT (2011).
Del mismo modo, definir que las AFP no inviertan en empresas que sean sancionadas por colusión, prácticas antisindicales, transgresión grave a normas medioambientales, vulneración de derechos de los consumidores, grave deterioro de ecosistemas o biodiversidad, financiamiento ilegal de la política, etc. Como criterios positivos se podrían considerar favorecer a aquellas empresas que colaboren activamente en el logro de los ODS y demuestren un buen desempeño, buenas prácticas y altos estándares laborales, medioambientales, con proveedores, consumidores, comunidad, Estado. En definitiva, premiar a aquellas empresas que más contribuyan al bien común (Felber, 2012).

\section{Referencias}

CEPAL. 2016. Agenda 2030 y los Objetivos de Desarrollo Sostenible: una oportunidad para América Latina y El Caribe. Disponible en http:// repositorio.cepal.org/bitstream/ handle/11362/40155/1/S1600682 es.pdf

Comisión Asesora Presidencial sobre el Sistema de Pensiones (Comisión de Pensiones). 2015. La opinión y percepción del sistema de pensiones en Chile. Santiago, Chile. Disponible en http://www.comisionpensiones.cl/Documentos/ Capitulo? nombre $=$ fgAvAEMAbwBUAHQAZQBUAHQALWBJAGOAYQBnAGUAbgBIAHMALWBDAGEACABpAHQAdQBsAG8AcwAvAEMAQQBQAF8ANgAuAHAAZABmAA\%3D\%3D

Etxezarreta et al. 2015. Innovación Social, Políticas Públicas y Economía Social y Solidaria. REAS-Euskadi. Disponible en http://www. economiasolidaria.org/files/Papeles_ES_5.pdf

Felber, C. 2012. La Economía del Bien Común. Deusto Ediciones. 288 pp. López, F. 2016. Industria de AFP:
¿Cuánto gana y cuánto debería ganar? Revista de Análisis Económico (RAE) Vol. 31 No 2. Facultad de Economía y Negocios, Universidad Alberto Hurtado - Georgetown University.

OCDE (21 de mayo de 2015). In It Together: Why Less Inequality Benefits All...in Chile. Obtenido de https://www.oecd.org/chile/ OECD2015-In-It-Together-Highlights-Chile.pdf

OIT. 2011. Seguridad Social para la justicia social y una globalización equitativa. Disponible en http://www.ilo. org/wcmsp5/groups/public/@ed_ norm/@relconf/documents/meetingdocument/wcms_154235.pdf

Schweickart, D. 2011. Crisis económica y ecológica: causas, causas profundas, soluciones. First International Conference on Transformation. Institute for Critical Social Analysis of the Rosa Luxemburg Foundation. P.35

Superintendencia de Pensiones. 2013. Número de cotizantes y cotizaciones en sistema de capitalización individual. Obtenido de http://www. spensiones.cl/safpstats/stats/. sc.php?_cid=10

Superintendencia de Pensiones. Régimen de Inversiones de los Fondos de Pensiones. Régimen vigente a partir del 30 de julio de 2013. Disponible en https://www.spensiones.cl/portal/regulacion/582/ w3-article-10257.html

Superintendencia Valores y Seguros. 2016. Listado de Emisores de valores. Obtenido de http://www. svs.cl/institucional/mercados/consulta.php? mercado $=\mathrm{V} \&$ Estado $=-$ VI\&entidad $=$ RVEMI

Second Swedish National Pension Fund-AP2 (December 2015). Second AP Fund Corporate Governance Policy. Obtenido de http:// www.ap2.se/globalassets/hallbarhet-agarstyrning/corporate-governance-policy.pdf 